\title{
Electrochemistry of Vitamin E Hydro-Alcoholic Solutions
}

\author{
Cristiano Giacomelli, Fernando Carlos Giacomelli, Luciano Ortigara Alves, Ana Karina Timbola \\ and Almir Spinelli
}

\author{
Departamento de Química, Universidade Federal de Santa Catarina, 88040-900, Florianópolis - SC, Brazil
}

\begin{abstract}
O comportamento eletroquímico da vitamina E em meio hidro-alcoólico foi estudado na faixa de pH 3,1-12,1 aplicando-se as técnicas voltametria cíclica, eletrólise com potencial controlado e espectroscopias UV-Vis, IR e ${ }^{13} \mathrm{C} \mathrm{RMN}$. Observou-se que a presença de água tem consequiências importantes na estabilidade química das espécies geradas eletroquimicamente. Em meio hidro-alcoólico e sobre eletrodos de carbono vítreo, a vitamina $\mathrm{E}$ apresenta três picos de oxidação, enquanto que apenas um pico é observado em outros solventes. Embora a reação eletroquímica no primeiro pico seja a mesma na presença e na ausência de água, a qual compreende a transferência de dois elétrons em uma etapa, duas reações eletroquímicas e três químicas subseqüentes ao primeiro pico foram pela primeira vez estabelecidas com base em evidências eletroquímicas em meio hidro-alcoólico. Estes resultados são considerados muito importantes levando-se em consideração o papel mediador na transferência de elétrons entre a fase aquosa e lipídica que a vitamina E exerce no organismo.
\end{abstract}

The electrochemistry of vitamin E hydro-alcoholic solutions of $\mathrm{pH} 3.1$ to 12.1 was studied by cyclic voltammetry, controlled potential electrolysis, thin layer chromatography and UV-Vis, IR and ${ }^{13} \mathrm{C}$ NMR spectroscopy. The presence of water was found to have important implications on the chemical stability of electrogenerated species. Vitamin E exhibits three oxidation peaks in hydroalcoholic solutions at glassy carbon electrodes in contrast to just a single peak in other solvents. Although the electrochemical reaction at the first peak was found to be the same in presence and in absence of water, which is a one-step two-electron transfer process, two heterogeneous electrochemical reactions and three homogeneous chemical reactions following this peak were established based on electrochemical evidences for the first time in alcohol aqueous conditions. This insight is considered to be very important provided the mediator character of vitamin $\mathrm{E}$ in the electron transfer between aqueous and lipid phase in the organism.

Keywords: vitamin E, electrochemistry, antioxidants

\section{Introduction}

Vitamin E ( $\alpha$-tocopherol, Figure 1) has prompted a host of many chemical and biological studies due to the widespread occurrence in the nature and also the natural antioxidant action. ${ }^{1,2}$ Tocopherols are present in biomembranes and are efficient free radical scavengers through electron transfer processes, inhibiting the lipid peroxidation. ${ }^{1,3}$ The inherent vitamin E biological relevance is related to the mediator character in the electron transfer between aqueous (where low molecular weight antioxidants are present) and lipid phase (practically apolar). ${ }^{1}$ Despite this, the electrochemical behavior of vitamin $\mathrm{E}$ has been almost always studied in

* e-mail: spin@qmc.ufsc.br<smiles>[R]C1(C)CCc2c([13CH])c(O)c(C)c([18OH])c2O1</smiles>

$$
\mathrm{R}=\mathrm{C}_{16} \mathrm{H}_{33} \text { (phytyl side chain) }
$$

Figure 1. Chemical structure of vitamin E ( $\alpha$-tocopherol; $\alpha$-TOH).

organic solvents due to its solubility characteristics. Organic solvents can model some biological properties, nevertheless sometimes roughly. The stability of intermediate species originated by oxidation reactions is substantially different depending on the surroundings, ${ }^{4}$ offering a very rich chemistry as consequence. ${ }^{3-11}$ In this way, the knowledge of its electrochemical behavior in more 
biological-like conditions is relevant to get insight into vitamin $\mathrm{E}$ action as antioxidant. The proton concentration influence on the antioxidant activity, ${ }^{12,13}$ for example, is an important subject that is not satisfactorily approached in electrochemical measurements in organic media. A very attractive way to overcome this problem is that used recently by Wain et al. ${ }^{14}$ who investigated the biphasic redox chemistry of vitamin E immobilized as microdroplets on a basal plane pyrolytic graphite electrode in aqueous media.

The aim of this work is to contribute for the understanding of vitamin E electrochemistry in hydroalcoholic solutions at a glassy carbon electrode. It should be mentioned that in the literature most of the investigations were carried out using platinum ${ }^{2,3,15-17}$ working electrodes, whereas rarely were glassy ${ }^{18,19}$ or paste ${ }^{20-22}$ carbon electrodes. Undoubtedly, new implications may evolve as result, and we indeed show here two novel oxidation peaks for the electrochemical oxidation of vitamin $\mathrm{E}$ dissolved in hydro-alcoholic solutions. Along with electrochemical evidences, ${ }^{13} \mathrm{CNMR}$, IR, UV-Vis and thin layer chromatography techniques were employed in order to interpret the results and propose a speculative mechanism, which is left for further and open discussion.

\section{Experimental}

\section{Chemicals}

All the reagents used in this study were of analytical grade acquired from Fluka (vitamin E), Merck $\left(\mathrm{H}_{3} \mathrm{PO}_{4}\right.$, $\mathrm{K}_{2} \mathrm{HPO}_{4}, \mathrm{KH}_{2} \mathrm{PO}_{4}, \mathrm{KOH}$ ), Grupo Química (ethanol) and Aldrich $\left(\mathrm{NH}_{4} \mathrm{PF}_{6}\right)$. They were used without previous purification. Distilled and deionized water was used for all solution preparations.

\section{Cyclic voltammetry}

Cyclic voltammograms were recorded using a glassy carbon working electrode as previously described. ${ }^{12}$ Working solutions containing $\mathrm{K}_{2} \mathrm{HPO}_{4}$ or $\mathrm{KH}_{2} \mathrm{PO}_{4}(0.1 \mathrm{~mol}$ $\mathrm{L}^{-1}$ ) with adjusted $\mathrm{pH}$ with $\mathrm{KOH}$ or $\mathrm{H}_{3} \mathrm{PO}_{4}$ and ethanol 1:1 $(\mathrm{v} / \mathrm{v})$ were used. Vitamin $\mathrm{E}$ was directly added $(10 \mu \mathrm{L})$ to the $15 \mathrm{~mL}$ cell from a stock $1.5 \mathrm{~mol} \mathrm{~L}^{-1}$ solution in ethanol after attainment of a cyclic voltammogram of the electrode immersed in a vitamin $\mathrm{E}$ free solution. It should be noted that the resulting solution becomes turbid when vitamin $\mathrm{E}$ is added owning to its solubility. However, the results herein were found to be completely reproducible. The working electrode used in potential controlled coulometry was a reticulated glassy carbon mounted in a non-divided electrochemical cell. All the potentials in text are quoted to the Saturated Calomel Electrode (SCE).

Column chromatography and characteristics of the products

In a typical procedure, $150 \mathrm{~mL}$ of a potential-controlled electrolyzed $1.0 \mathrm{mmol} \mathrm{L}^{-1}$ vitamin $\mathrm{E}$ alcoholic solution was evaporated. Thin layer chromatography (TLC) of the resulting oil revealed the presence of two spots (vitamin E and a more polar compound). Subsequently, the products were purified chromatographically in a silica column using mixtures of hexane/ethyl acetate (from 100/0 to 70/30 (v/v)) as eluent. Thirty fractions were collected and analyzed by TLC, then revealing the presence of two compounds (A and $\mathrm{B}$ ) in addition to vitamin E. Fractions containing the same compound (A or B) were grouped for subsequent analyses. Compound A was characterized using ${ }^{13} \mathrm{C}$ NMR (50 MHz, Brucker DRX), IR (Perkin Elmer FT16PC) and UV-Vis (Hitachi U-3000). In the case of B, only a small drop of a brown oil could be isolated, being not possible to properly handle with for further studies.

3,4,5-trimethyl-2-(3-hydroxy-3,7,11,15-tetramethylhexadecan-1-yl)-p-benzoquinone (tocoquinone)

IR (film) $v_{\max } / \mathrm{cm}^{-1}: 3490,3264,2927,2864,2723$, 1641, 1461, 1376, 1304, 1219, 1162, 1107, 933, 876, 832, 716, 646. ${ }^{13} \mathrm{C}$ NMR ( $d$-acetone) $\delta 22.4(\mathrm{C}-4), 33.8(\mathrm{C}-2 \mathrm{a})$, 43.2 (C-3), 72.3 (C-2), 140.8; 141.2 (C-5 and C-7; C-8), 145.9 (C-4a), $187.8 ; 188.3$ (C-6; C-8a). ${ }^{4}$ The numbering of carbon atoms is shown in Figure 1.

\section{Results}

Figure 2 shows a typical cyclic voltammogram at a glassy carbon working electrode in $\mathrm{pH} 7.4$ hydro-alcoholic 1:1 (v/v) solution containing $1.0 \mathrm{mmol} \mathrm{L}^{-1}$ vitamin $\mathrm{E}$ for a scan rate $(v)$ of $100 \mathrm{mV} \mathrm{s}^{-1}$. The inset depicts a cyclic voltammogram recorded in absolute ethanol by employing the same electrochemical parameters in order to obtain data concerning the solvent influence on the chemical stability of generated species. In first positive going scan, three oxidation processes are pointed out in hydroalcoholic medium $\left(\mathrm{E}_{\mathrm{p}}{ }^{\mathrm{I}}=+0.17 \mathrm{~V}, \mathrm{E}_{\mathrm{p}}{ }^{\mathrm{II}}=+0.84 \mathrm{~V}\right.$ and $\mathrm{E}_{\mathrm{p}}{ }^{\mathrm{III}}=$ $+1.04 \mathrm{~V})$, whereas just one peak is observed in ethanol $\left(\mathrm{E}_{\mathrm{p}}{ }^{\mathrm{I}}\right.$ $=+0.50 \mathrm{~V})$. The similarity concerning peak I potential range and the respective current intensity $\left(\mathrm{i}_{\mathrm{p}}{ }^{\mathrm{I}}\right)$ suggests that the same electrochemical reaction takes place in that region in both cases hydro-alcoholic and ethanol. In the reverse 


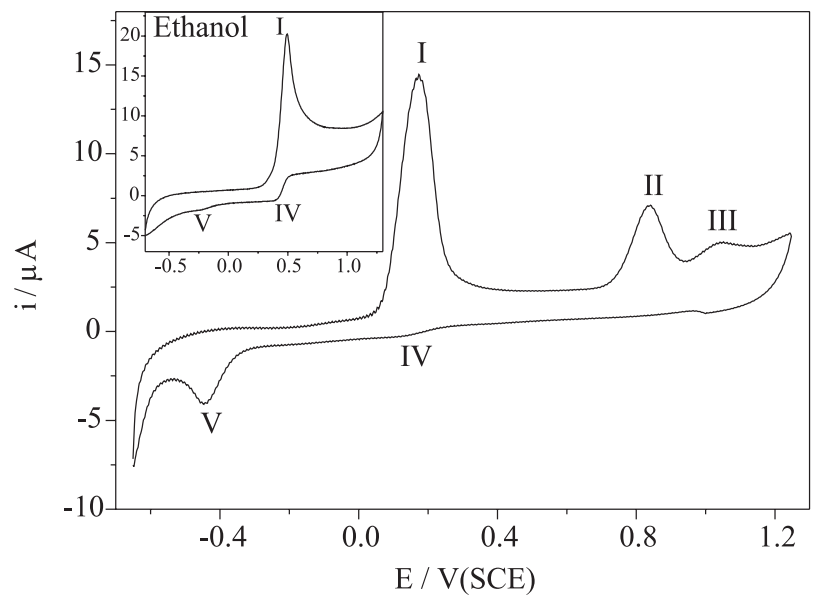

Figure 2. Cyclic voltammogram for $1.0 \mathrm{mmol} \mathrm{L}^{-1}$ vitamin $\mathrm{E}$ in ethanol/water 1:1 (v/v) solution with $\mathrm{pH} 7.4$ at a glassy carbon electrode for $v=100 \mathrm{mV} \mathrm{s}^{-1}$. The inset shows a cyclic voltammogram recorded in ethanol with $\mathrm{NH}_{4} \mathrm{PF}_{6}$ as supporting electrolyte (the electrochemical parameters are identical).

going scan, two reduction processes can be perceived in both hydro-alcoholic $\left(\mathrm{E}_{\mathrm{p}}^{\mathrm{IV}}=+0.16 \mathrm{~V}\right.$ and $\left.\mathrm{E}_{\mathrm{p}}^{\mathrm{V}}=-0.45 \mathrm{~V}\right)$ and ethanol $\left(\mathrm{E}_{\mathrm{p}}^{\mathrm{IV}}=+0.16 \mathrm{~V}\right.$ and $\left.\mathrm{E}_{\mathrm{p}}^{\mathrm{V}}=-0.24 \mathrm{~V}\right)$ solutions, but with different intensities. The overall voltammetric response shown in Figure 2 is similar to that observed by Wain et al. ${ }^{14}$ for the biphasic oxidation of vitamin $\mathrm{E}$ microdroplets immobilized on graphite electrodes immersed in aqueous solutions.

Figure 2 clearly convinces that water deeply influences the voltammetric profile of vitamin E, increasing drastically the current at peak $\mathrm{V}$ and producing two novel oxidation peaks (II and III) in the positive scan. Hence, it is worthwhile to evaluate the influence of $\mathrm{pH}$ on the voltammetric profile. Figure 3 shows cyclic voltammograms at a glassy carbon electrode in $1.0 \mathrm{mmol} \mathrm{L}^{-1}$ vitamin $\mathrm{E}$ for $v=100 \mathrm{mV} \mathrm{s}^{-1}$ for $\mathrm{pH}$

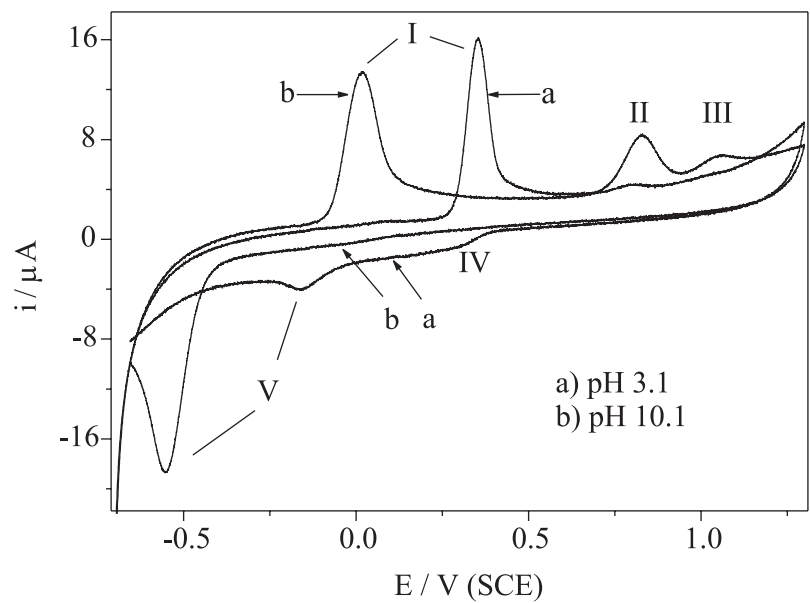

Figure 3. Cyclic voltammogram for $1.0 \mathrm{mmol} \mathrm{L}^{-1}$ vitamin $\mathrm{E}$ in ethanol/water $1: 1(\mathrm{v} / \mathrm{v})$ solution with distinct $\mathrm{pH}$ at a glassy carbon electrode for $v=100 \mathrm{mV} \mathrm{s}^{-1}$.
3.1 and 10.1 (only two curves are exhibited for the sake of clarity), based on which it can be visibly concluded that solution $\mathrm{pH}$ plays a major role on the chemistry of electrogenerated species. The following remarks are evident in Figure 3 when the solution $\mathrm{pH}$ is progressively augmented from 3.1 (curve a) to 10.1 (curve b): $i$ ) the current intensity related to peak $I\left(\mathrm{i}_{\mathrm{p}}{ }^{\mathrm{I}}\right)$ slightly decreases with concurrent shift of $\mathrm{E}_{\mathrm{p}}{ }^{\mathrm{I}}$ towards more negative values (i.e., the nucleophilicity of the organic compound increases ${ }^{23}$ and its antioxidant activity is thermodynamically favored with the increase in the $\mathrm{pH})$; ii) the current associated to peaks II ( $\left.\mathrm{i}_{\mathrm{p}}^{\text {III }}\right)$ and III ( $\mathrm{i}_{\mathrm{p}}^{\text {III) }}$ increases; iii) the shoulder IV disappears and iv) the current of peak $\mathrm{V}\left(\mathrm{i}_{\mathrm{p}}^{\mathrm{V}}\right)$ dramatically increases with simultaneous displacement of $\mathrm{E}_{\mathrm{p}}^{\mathrm{V}}$ towards more negative values.

Figure 4A shows the linear dependence of $\mathrm{E}_{\mathrm{p}}{ }^{\mathrm{I}}$ and $\mathrm{E}_{\mathrm{p}}^{\mathrm{V}}$ on the solution $\mathrm{pH}$ (data extracted from voltammograms recorded in the same conditions as for Figure 3) with $\delta$ Ep
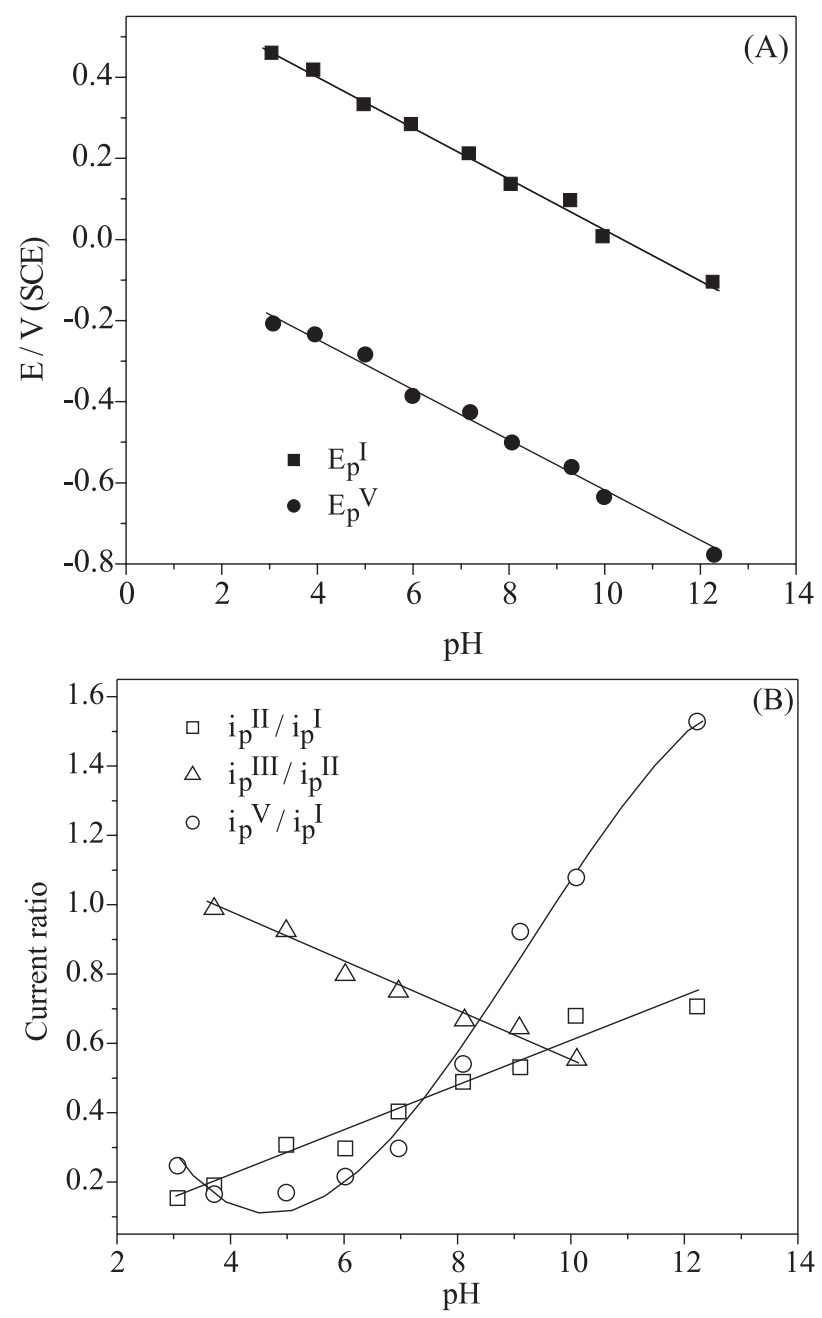

Figure 4. (A) Peak I and V potential as function of $\mathrm{pH}$ and (B) current ratio variation as function of $\mathrm{pH}$ (data extracted from 1.0 mmol $\mathrm{L}^{-1}$ vitamin E hydro-alcoholic 1:1 (v/v) cyclic voltammograms for $v=100 \mathrm{mV} \mathrm{s}^{-1}$ ). 
$\delta \mathrm{pH}^{-1} \sim 60 \mathrm{mV} \mathrm{pH}^{-1}$. This slope has been usually determined for phenolic systems in aqueous media ${ }^{24}$ which stands for electrochemical reactions followed by deprotonation involving the same number of electrons (n) and protons (m). Peaks II and III are practically not changed by solution $\mathrm{pH}$ (Figure 3), which means that proton species are not involved in these electrochemical processes.

Figure 4B shows the current ratio $\left(i_{\mathrm{p}}{ }^{\mathrm{II}} / \mathrm{ip}^{\mathrm{I}} ; \mathrm{i}_{\mathrm{p}}{ }_{\mathrm{III}} / \mathrm{ip}^{\mathrm{II}}\right.$; $\mathrm{i}_{\mathrm{p}} \mathrm{V} / \mathrm{ip}^{\mathrm{I}}$ ) variation as function of $\mathrm{pH}$ (data extracted from voltammograms recorded for $\left.v=100 \mathrm{mV} \mathrm{s}^{-1}\right)$. The $\mathrm{i}_{\mathrm{p}}{ }^{I I} / \mathrm{i}_{\mathrm{p}}{ }^{\mathrm{I}}$ current ratio dependence on $\mathrm{pH}$ is virtually linear, increasing as $\mathrm{pH}$ increases, the opposite behavior being observed for $\mathrm{i}_{\mathrm{p}}$ III $/ \mathrm{i}_{\mathrm{p}}$ II. In the case of $\mathrm{i}_{\mathrm{p}} \mathrm{V} / \mathrm{i}_{\mathrm{p}}{ }^{\mathrm{I}}$, a slightly decrease occurs when $\mathrm{pH}$ is changed from 3.1 to 3.7 , exhibiting a minimum around $\mathrm{pH} 5.0$ and, afterwards, it significantly increases. These data in Figure 4B suggest the occurrence of at least three homogenous chemical reactions at the electrode/solution interface involving electrogenerated species (see Discussion).

Depending on the characteristics of each particular electrochemical system, the scan rate effect on cyclic voltammetric profile is an important tool to evaluate the presence of homogenous chemical reactions perhaps following the electrochemical ones. ${ }^{24}$ Figure 5A shows typical cyclic voltammograms at a glassy carbon electrode in $1.0 \mathrm{mmol} \mathrm{L}^{-1}$ vitamin E hydro-alcoholic 1:1 (v/v) $\mathrm{pH}$ 7.4 solutions recorded for different $v$ (for the sake of clarity, only four voltammograms are given). In general, all the current peak intensities increased as function of $v$ as expected, ${ }^{23,24}$ and all the peak potentials were found to be influenced by $v$ describing non-reversible electrochemical reactions. The inset in Figure 5A shows that the current intensity relative to peak I linearly depended on the square root of the scan rate in the range $50-500 \mathrm{mV} \mathrm{s}^{-1}$, which is a behavior characteristic for diffusion-controlled processes. ${ }^{23,24}$ Figure 5B shows the current ratio $\left(\mathrm{i}_{\mathrm{p}}{ }^{\mathrm{I}} / \mathrm{ip}\right.$; $\mathrm{i}_{\mathrm{p}}^{\mathrm{III}} / \mathrm{ip}^{\mathrm{II}}$ ) variation as function of $v$ for $\mathrm{pH} 7.4$ solutions. In Figure $5 \mathrm{~B}$, it is intended to show that the number of electrons at peak II corresponds to a half of peak I, given that $\mathrm{i}_{\mathrm{p}}{ }^{\mathrm{II}} / \mathrm{i}_{\mathrm{p}}{ }^{\mathrm{I}}$ is approximately 0.5 for all conditions. Concerning the $\mathrm{i}_{\mathrm{p}}^{\mathrm{III}} / \mathrm{i}_{\mathrm{p}}^{\text {II }}$ current ratio dependence on $v$, it suggests the occurrence of homogeneous chemical reaction involving the specie formed at peak II.

It has been proposed $d^{14,19,20,24,25}$ that a homogeneous chemical reaction of hydrolysis following peak I (in water containing solutions) gives to tocoquinone (an electrochemically active compound) as product. So assuming, at least one electrochemical process in addition to those already shown herein is presumably expected. Indeed, as depicted in Figure 6A for pH 3.1 (chosen owing to its comprehensibility) solutions, for all cycles following
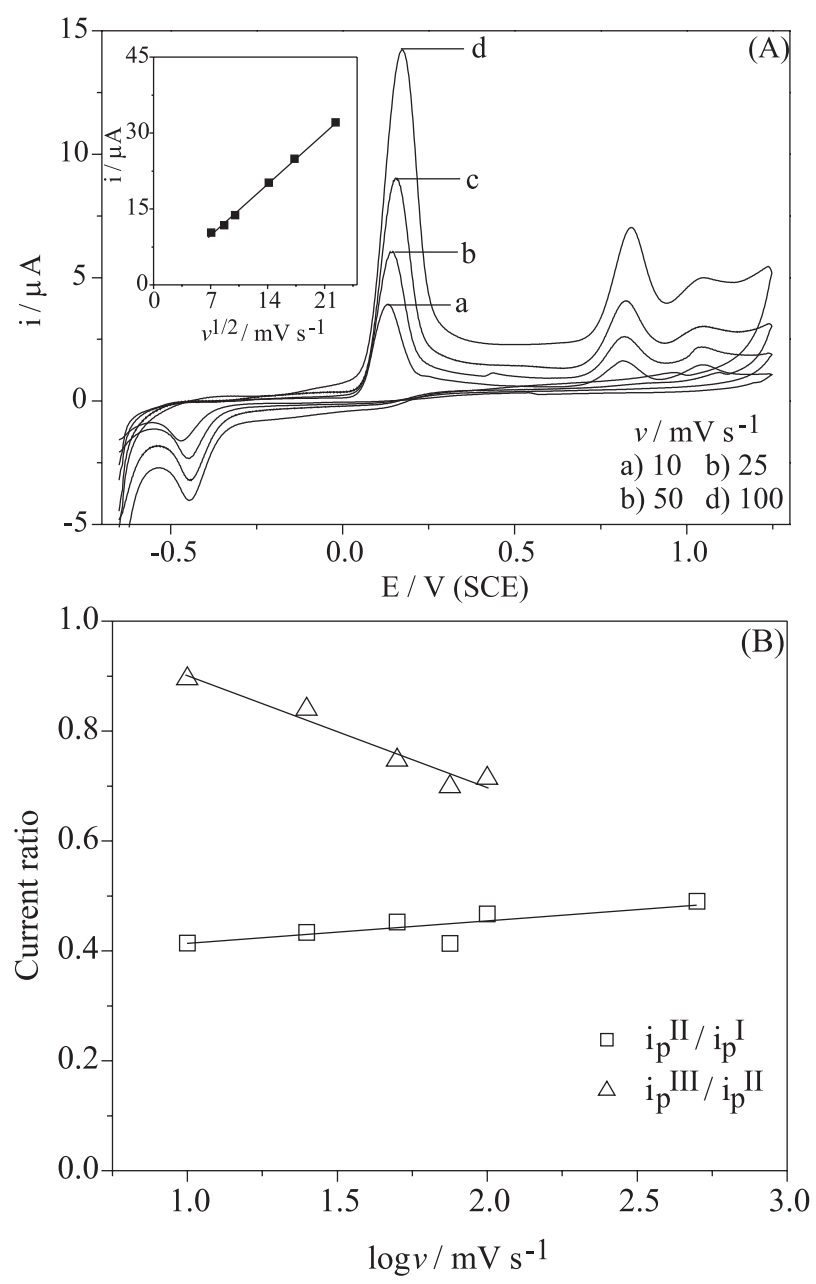

Figure 5. (A) Cyclic voltammograms for $1.0 \mathrm{mmol} \mathrm{L}^{-1}$ vitamin $\mathrm{E}$ in ethanol/water 1:1 (v/v) pH 7.4 solution at a glassy carbon electrode for different $v$ and (B) current ratio variation as function of $v$ based on data extracted from the voltammograns showed in Figure 5A.

the first one, the peak VI could be pointed out, which means that it should correspond to the oxidation of an electroactive specie formed during the first cycle. In order to clarify its relationship with the other voltammetric peaks, an experiment employing a modified potential/time perturbation program was carried out (Figure 6B). Initially, the cycle $\mathbf{1}$ was recorded between -0.70 and $+1.30 \mathrm{~V}$. Afterwards, the anodic switching potential $\left(\mathrm{E}_{\lambda, \mathrm{a}}\right)$ was shifted to $0.00 \mathrm{~V}$, then registering cycles 2 and $\mathbf{3}$. Later, $\mathrm{E}_{\mathrm{l}, \mathrm{a}}$ was shifted again to $-0.20 \mathrm{~V}$, being the cycles $\mathbf{4}$ and $\mathbf{5}$ obtained in the $-0.7 \mathrm{~V}--0.2 \mathrm{~V}$ potential range. The outcome of this experiment (Figure 6B) revealed that peak VI is not present in the cycle $\mathbf{1}$. However, it is clearly noticed in the cycles $\mathbf{2}$ and 3. Cycle $\mathbf{3}$ also demonstrates the interrelation between peaks $\mathrm{V}$ and VI, as long as cycle $\mathbf{3}$ has the same profile as cycle $\mathbf{2}$.

Controlled potential coulometry was performed in ethanol containing $1.0 \mathrm{mmol} \mathrm{L}^{-1}$ vitamin $\mathrm{E}$ at peak I. The 

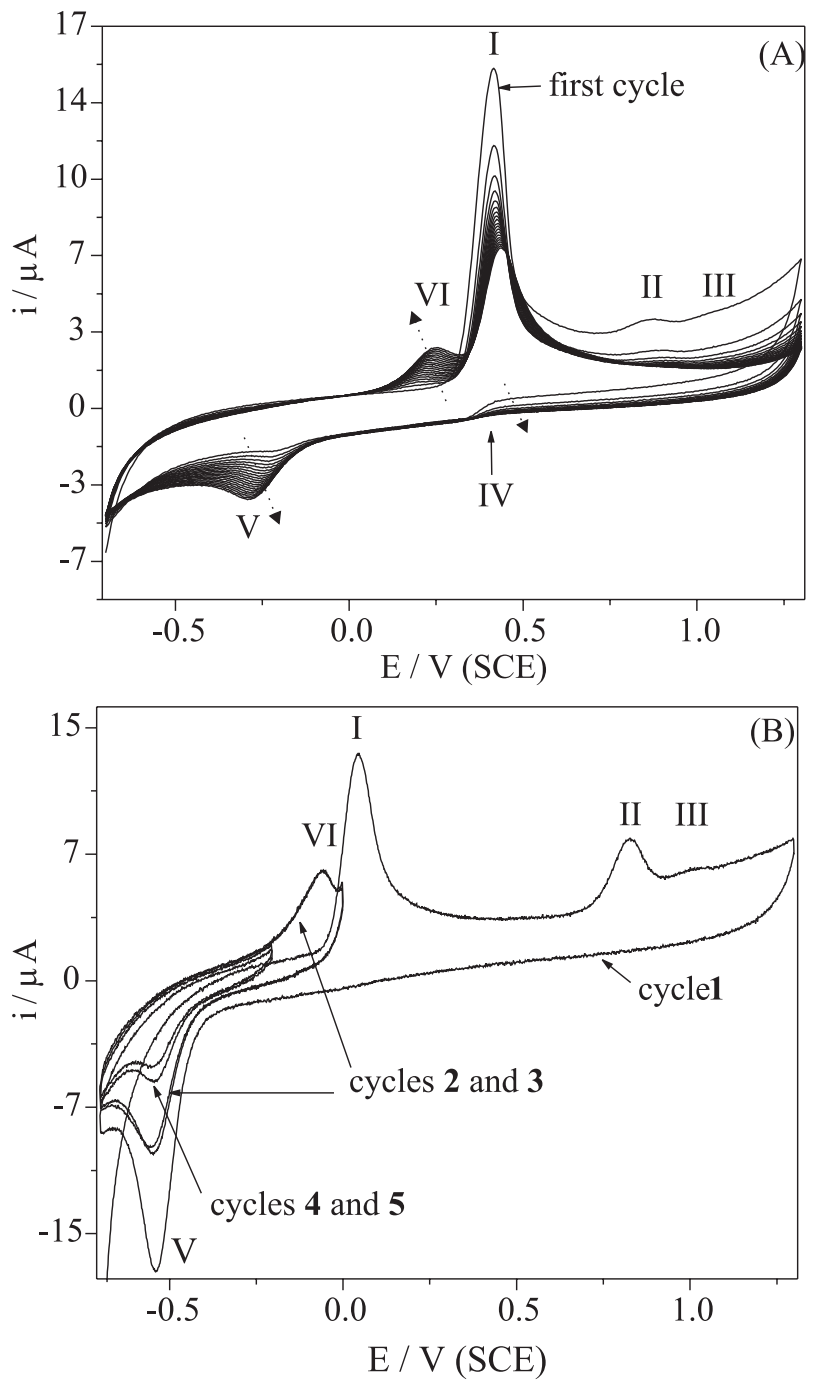

Figure 6. (A) Repetitive cyclic voltammetry at a glassy carbon electrode for $v=100 \mathrm{mV} \mathrm{s}^{-1}$ in $1.0 \mathrm{mmol} \mathrm{L}^{-1}$ vitamin $\mathrm{E}$ ethanol/water $1: 1(\mathrm{v} / \mathrm{v}) \mathrm{pH} 3.1$ solution and (B) at $\mathrm{pH} 10.1$ solution employing a modified potential/time perturbation program.

electrolysis progress was monitored using cyclic voltammetry (Figure 7). It is shown that, proportionally to the advancement of coulometry, the anodic peak I decreases, disappearing when the charge consumption becomes about 2 electrons per molecule of vitamin $\mathrm{E}$. The resulting electrolyzed solution was adequately handled in order to isolate and identify the products.

Figure 8 shows UV spectra for vitamin E (spectrum a), electrolyzed solution (spectrum b), and two chromatographically-resolved fractions (A and B (spectra c and d)). Vitamin E (spectrum a) exhibits two absorption bands at 223 and $292 \mathrm{~nm} .{ }^{26,27}$ Upon electrolysis (spectrum b), an new absorption band appears around $265 \mathrm{~nm}$, meanwhile that at $292 \mathrm{~nm}$ becomes less pronounced (observe the relationship between intensities instead of intensities itself in Figure 8 since concentration of each compound is different) indicating the consumption of vitamin E. When the electrolyzed solution was resolved chromatographically, practically a single compound (oil) was found (fraction A), though a minor amount of another product (fraction B) could be also verified. In Figure 8, the absorption spectrum for fraction A (spectrum c) is characteristic for tocoquinone, ${ }^{26,27}$ as also was indicated by ${ }^{13} \mathrm{C}$ NMR and IR spectroscopy. Concerning fraction B (spectrum d), it was not possible to obtain a reasonable quantity of product for further characterization. However, it is interesting to notice that fraction B shows the absorption characteristics of both vitamin E (223 and 292 $\mathrm{nm})$ and tocoquinone (265 $\mathrm{mn})$.

The controlled potential electrolysis shown above was performed in ethanol instead of hydro-alcoholic solution, which is the purpose of this work. Indeed, we tried to carry
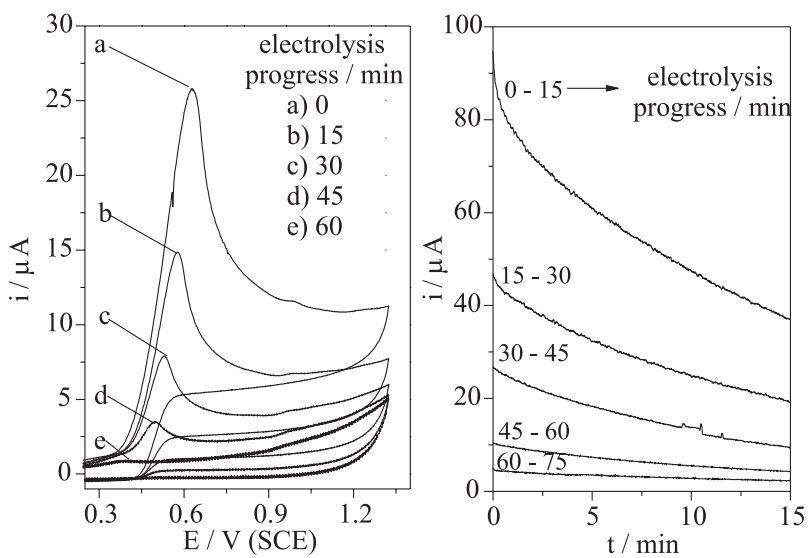

Figure 7. Linear sweep voltammograms for $1.0 \mathrm{mmol} \mathrm{L}^{-1}$ vitamin $\mathrm{E}$ in ethanol at a glassy carbon electrode for $v=100 \mathrm{mV} \mathrm{s}^{-1}$ after 0 (a), 15 (b) 30 (c), 45 (d), 60 (e) min of potential-controlled bulk electrolysis. The inset shows the current-time curves during electrolysis.

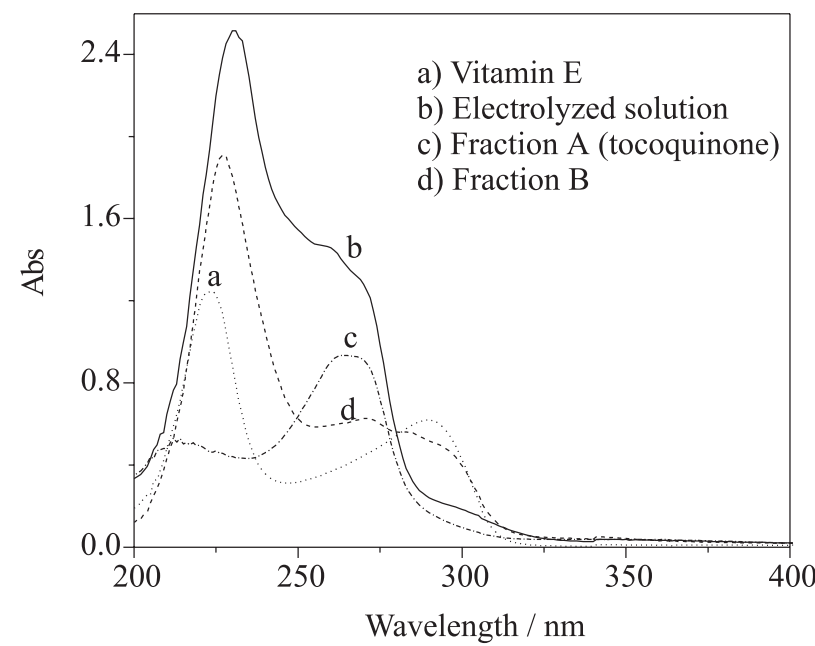

Figure 8. UV spectra for vitamin E (spectrum a), potential-controlled electrolyzed solution (spectrum b), and two chromatographically-resolved fractions A (spectrum $\mathbf{c}$ - tocoquinone) and B (spectra d). 
it out in a hydro-alcoholic medium, but the current decreased almost instantaneously due to the poisoning of the working electrode, probably owing to the low solubility of reagents or oxidized products in this solvent mixture. Therefore, in order to confirm the number of electrons concerned at peak I in our work, caffeic acid, whose electrochemistry is kwon in aqueous solutions, ${ }^{12}$ was added to cell in the same concentration $\left(1.0 \mathrm{mmol} \mathrm{L}^{-1}\right)$ as for vitamin $\mathrm{E}$. The resulting cyclic voltammogram is shown in Figure 9, which reveals that caffeic acid does not interact with vitamin $\mathrm{E}$ or vitamin $\mathrm{E}$ derivative species, so that the sum of vitamin $E$ and caffeic acid voltammetric profiles is observed. Most importantly in Figure 9 is the current intensity of peak I for vitamin $\mathrm{E}$ and caffeic acid that suggests the same number of electrons being transferred in both cases.

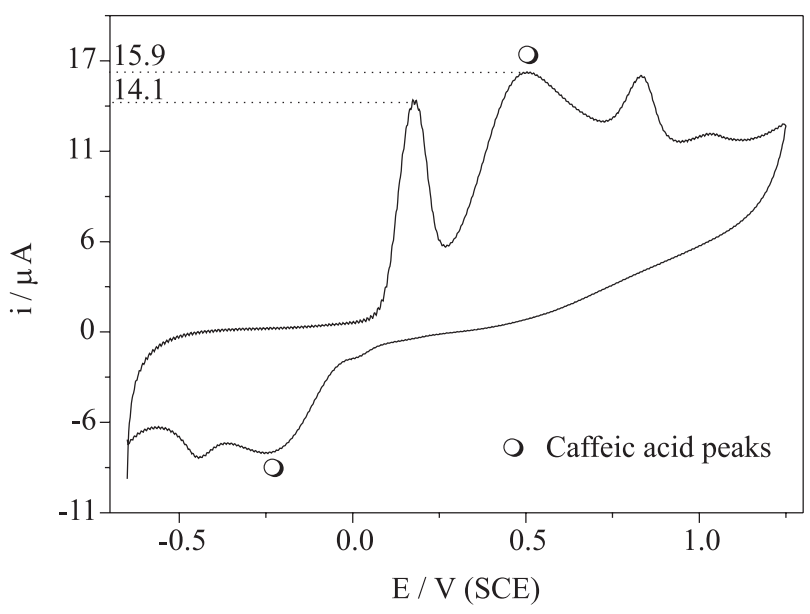

Figure 9. Cyclic voltammogram for $1.0 \mathrm{mmol} \mathrm{L}^{-1}$ vitamin $\mathrm{E}$ and 1.0 $\mathrm{mmol} \mathrm{L}{ }^{-1}$ caffeic acid in ethanol/water 1:1 (v/v) solution with $\mathrm{pH} 7.4$ at a glassy carbon electrode for $v=100 \mathrm{mV} \mathrm{s}^{-1}$.

\section{Discussion}

It is well-known that the chemical stability of vitamin E related species is substantially different depending on the surroundings (for instance, the solvent) ${ }^{4}$ resulting in a very rich chemistry as consequence. ${ }^{3-11}$ In this work, we have indeed observed a number of novel characteristics for the electrochemistry vitamin $\mathrm{E}$ in hydro-alcoholic solutions. It is clear in Figure 2 that water deeply influences the voltammetric profile of vitamin $\mathrm{E}$ through a drastic increase in the peak $\mathrm{V}$ current intensity, also producing two novel oxidation peaks (II and III) in the positive scan in homogeneous solutions. These peaks (II and III) were not reported before in these conditions, and they may certainly have implications for the antioxidant activity of vitamin $\mathrm{E}$ in biological conditions, provided that the fate of electrogenerated species is an important question in the biological system. ${ }^{28}$ Zhu and Zhang, ${ }^{19}$ who studied the electrochemistry of vitamin $\mathrm{E}$ in methanol/acetate buffer solution 4:1 (v/v), did not report the occurrence of peaks II and III probably because an anodic switching potential $\left(\mathrm{E}_{2, \mathrm{a}}\right)$ of $+0.80 \mathrm{~V} / \mathrm{Ag} / \mathrm{AgCl}$ was applied, as did Jaiswal et al. ${ }^{21}$ in surfactant/ethanol/water solutions. In addition, vitamin $\mathrm{E}$ has been found to present just a single oxidation process in other solvent systems or working electrodes. ${ }^{2,3,15-17,22}$ Recently, Wain et al. ${ }^{14}$ observed the existence of peak II in the biphasic oxidation of vitamin $\mathrm{E}$.

The solution $\mathrm{pH}$ was found to be the foremost variable in the system under study, as shown in Figures 3 and 4. The dependence of $\mathrm{E}_{\mathrm{p}}^{\mathrm{I}}$ and $\mathrm{E}_{\mathrm{p}}^{\mathrm{V}}$ on the solution $\mathrm{pH}$ in Figure $4 \mathrm{~A}\left(\delta \mathrm{Ep} \delta \mathrm{pH}^{-1}=-60 \mathrm{mV} \mathrm{pH}^{-1}\right)$ is distinguishing for electrochemical reactions followed by deprotonation involving the same number of electrons (n) and protons (m). Peak I is a two-electron process (as determined by potential-controlled electrolysis (Figure 7) and by adding caffeic acid to the electrochemical cell (Figure 9)) and, therefore, an explanation (based on vitamin E structure Figure 1) for the slope obtained in this work is not straightforward. Two two-electron oxidized intermediates would be the dienone cation $(\mathrm{n}=2 \text { and } \mathrm{m}=1)^{2,19,20,24}$ and an orto-quinone methide $(\mathrm{n}=2$ and $\mathrm{m}=2){ }^{4}$ Provided that both the intermediates can give to the herein well characterized final compound at peak I (tocoquinone), the $\delta$ Ep $\delta \mathrm{pH}^{-1}$ value would be easily explained by the formation of orto-quinone methide. On the other hand, a $60 \mathrm{mV} \mathrm{pH}^{-1}$ slope may arise from the fact that the turbid low ionic strength $\left(0.05 \mathrm{~mol} \mathrm{~L}^{-1}\right)$ working solution can potentially provoke an appreciable ohmic drop, resulting in an overestimated $\delta \mathrm{Ep} \delta \mathrm{pH}^{-1}$ slope.

Based on the electrochemical evidences shown herein, it was possible to establish a quite detailed mechanism sketch (Scheme 1) for vitamin E electro-oxidation in hydroalcoholic medium, which is supported principally by data from Figures 4B, 5B, 6B, as it will be outlined in the sequence.

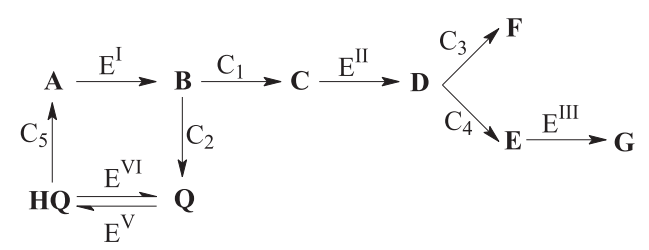

Scheme 1. Electrochemistry of vitamin E in hydro-alcoholic 1:1 (v/v) solutions $(\mathrm{E}=$ heterogeneous electrochemical reaction at a specific voltammetric peak; $\mathrm{C}=$ homogenous chemical reaction).

According to Scheme 1, the oxidation of vitamin E A at peak I (electrochemical reaction $\mathrm{E}^{\mathrm{I}}$ ) yields to product $\mathbf{B}$. The structure for $\mathbf{B}$ has been proposed to be a dienone 
cation produced by a two-electron $(\mathrm{n}=2)$ one-proton $(\mathrm{m}=$ 1) process. The dependence of $\mathrm{E}_{\mathrm{p}}^{\mathrm{I}}$ on the solution $\mathrm{pH}$ (Figure 4B) suggests, in contrast, $\mathrm{n}=\mathrm{m}=2$ (as shown above) standing for orto-quinone methide intermediate. However, we are not able to discern between these two possible structures (dienone cation and orto-quinone methide) because both of them can give to the compound obtained by controlled potential coulometry and other contributions from the solution (as ohmic drop) may contribute for perhaps the overestimated slope in Figure 4A. After being electrogenerated at peak I, the compound B undergoes a homogeneous chemical reaction $\left(\mathrm{C}_{1}\right)$ that produces an electroactive derivative $\mathbf{C}$, as put forward by the augmentation of $\mathrm{i}_{\mathrm{p}}{ }^{\mathrm{II}}$ (i.e., $\mathrm{i}_{\mathrm{p}}{ }^{\mathrm{II}} / \mathrm{i}_{\mathrm{p}}{ }_{\mathrm{p}}^{\mathrm{I}}$ ratio) as function of $\mathrm{pH}$ (Figure 4B). The kinetic of $\mathrm{C}_{1}$ is faster as $\mathrm{pH}$ increases, and so being $\mathrm{C}_{1}$ produces a higher amount of the electroactive derivative $\mathbf{C}$ (reagent for the electrochemical reaction $\mathrm{E}^{\mathrm{II}}$ ) that, therefore, results in an increase in $i_{p}{ }_{p}{ }^{I I}$, and in the $i_{p}{ }_{p}{ }^{I I} / i_{p}{ }_{p}$ ratio as consequence, as a function of $\mathrm{pH}$. The structure of $\mathbf{C}$ (as is the case for $\mathbf{D}, \mathbf{E}, \mathbf{F}$ and $\mathbf{G}$ ) could not be resolved since it was not possible to achieve bulk electrolysis in hydro-alcoholic medium, the only experimental condition where peak II and III are present.

The compound $\mathbf{D}$ is generated from $\mathbf{C}$ at peak II through an one-electron $\left(\mathrm{i}_{\mathrm{p}}{ }^{\mathrm{II}} / \mathrm{i}_{\mathrm{p}}{ }^{\mathrm{I}}\right.$ is 0.5 - Figure $5 \mathrm{~B}$, thus as $\mathrm{E}^{\mathrm{I}}$ is a two-electron process, $\mathrm{E}^{\mathrm{II}}$ should be one-electron) no-proton $\left(\mathrm{E}_{\mathrm{p}}^{\mathrm{II}}\right.$ is not influenced by $\mathrm{pH}$ - Figure 3 ) electrochemical reaction $\left(E^{I I}\right)$. The diminution of $i_{p}{ }_{p} I I / i_{p}$ II ratio as $p H$ increased in Figure 4B suggests that the compound $\mathbf{D}$ is chemically instable undergoing a homogenous chemical reaction $\left(\mathrm{C}_{3}\right)$, whose product $\mathbf{F}$ is electrochemically inactive. The kinetic associated to $\mathrm{C}_{3}$ reaction also depends on the $\mathrm{pH}$, being more accentuated as the proton concentration decreases (see the $\mathrm{i}_{\mathrm{p}}{ }_{\mathrm{III}} / \mathrm{i}_{\mathrm{p}}{ }_{\mathrm{p}}$ ratio as function of $\mathrm{pH}$ - Figure 4B). Thus, only the unreacted quantity of $\mathbf{D}$ is further oxidized at peak III ( $\left.\mathrm{E}^{\mathrm{III}}\right)$ giving to the product $\mathbf{E}$. Despite this, the occurrence of an additional homogeneous chemical reaction $\left(\mathrm{C}_{4}\right)$ between $\mathbf{D}$ and $\mathbf{E}$ is suggested by the $\mathrm{i}_{\mathrm{p}}{ }^{\mathrm{III}} / \mathrm{i}_{\mathrm{p}}{ }^{\mathrm{II}}$ current ratio dependence on $v$ in Figure 5B. Thereby, $\mathrm{C}_{4}$ should produce the reagent for $\mathrm{E}^{\mathrm{III}}$ and as scan rate is increased, the amount of reagent formed by means this reaction is lower due to shorter time interval, originating, as result, a lower $\mathrm{i}_{\mathrm{p}}{ }^{\mathrm{III}} / \mathrm{i}_{\mathrm{p}}{ }^{\mathrm{II}}$ ratio at low scan rates (Figure 5B).

The product of controlled potential coulometry at peak I was found to be the tocoquinone $\mathbf{Q}$ (see spectra data as in Figure 8) in agreement to the findings previously reported elsewhere in presence of water. ${ }^{14,19,20,24}$ The formation of tocoquinone is independent of peaks II and III as revealed by studying the influence of the anodic switching potentials (data not shown). The reaction pathway that gives to tocoquinone $\mathbf{Q}$ comprises the hydrolysis of $\mathbf{B}$ (reaction $\mathrm{C}_{2}$ - Scheme 1). Assuming that $\mathbf{B}$ has a dienone cation structure instead of orto-quinone methide, it was observed that $\mathrm{C}_{2}$ reaction exhibits a $\log \mathrm{k}-\mathrm{pH}$ profile with a minimum at $\mathrm{pH} 5.0,{ }^{24,25}$ which is, indeed, in agreement with the $\mathrm{i}_{\mathrm{p}} \mathrm{V} / \mathrm{i}_{\mathrm{p}}{ }^{\mathrm{I}}$ current ratio variation as function of $\mathrm{pH}$ (Figure 4B) which also shows the lowest values (i.e., the lowest $\mathrm{i}_{\mathrm{p}}{ }^{\mathrm{V}}$ and thus the lowest $\mathrm{i}_{\mathrm{p}}{ }^{\mathrm{V}} / \mathrm{i}_{\mathrm{p}}{ }^{\mathrm{I}}$ ratio) around $\mathrm{pH}$ 5.0. According to Scheme 1, the tocoquinone $\mathbf{Q}$ can be reduced at peak V (see for example Figure 6B) via a two-electron two-proton process (electrochemical reaction $\mathrm{E}^{\mathrm{V}}$ ) originating the respective hydroquinone HQ. Afterwards, HQ can be re-oxidized to $\mathbf{Q}$ at peak VI (electrochemical reaction $\mathrm{E}^{\mathrm{VI}}$ ). Note that this statement is fully supported by the voltammetric profiles in this work (for instance cycles $\mathbf{2}$ and $\mathbf{3}$ in Figure 6B), being also in agreement with the results previously communicated elsewhere in water containing medium. ${ }^{20,24,25}$

Finally, the presence of vitamin E A even after reoxidation of $\mathbf{H Q}$ to $\mathbf{Q}$ is evidenced by peak I during cycling in pH 3.1 solutions (see Figure 6A). It is believed that $\mathbf{H Q}$ can rearrange into $\mathbf{A}\left(\mathbf{C}_{5}\right.$ in Scheme 1$){ }^{19,26,29}$

\section{Conclusions}

According to the findings shown herein, the electrochemistry of vitamin E hydro-alcoholic solutions can be described as in Figure 10 (a detailed form of Scheme $1)$. The detached area highlights the novel chemical $\left(C_{1}\right.$,
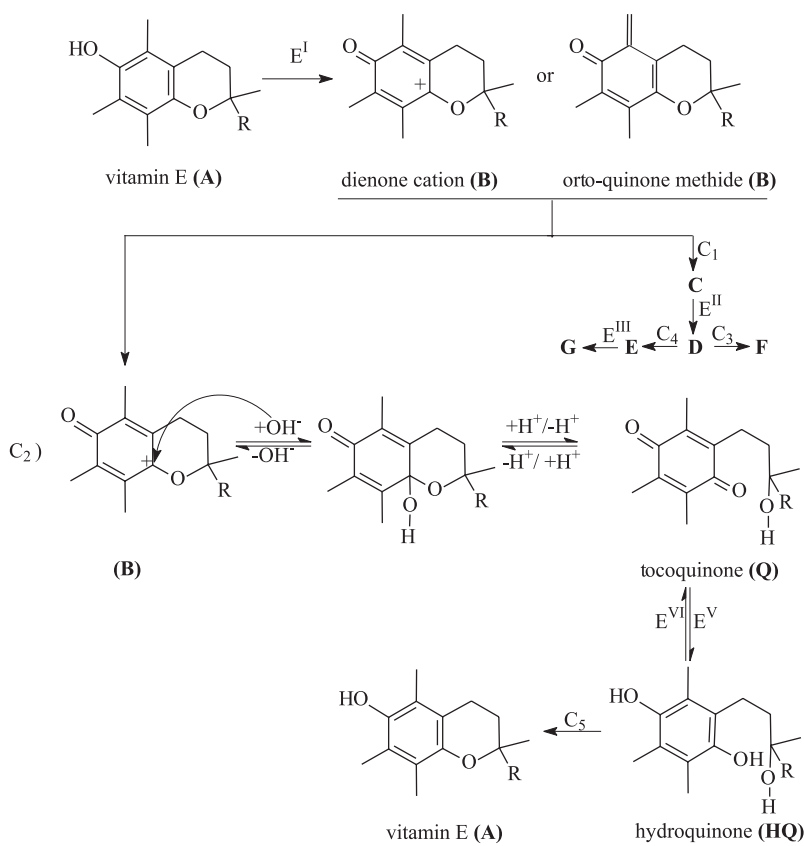

Figure 10. Electrochemical behavior of vitamin E in hydro-alcoholic solutions. 
$\mathrm{C}_{3}$ and $\mathrm{C}_{4}$ ) and electrochemical ( $\mathrm{E}^{\mathrm{II}}$ and $\mathrm{E}^{\mathrm{III}}$ ) reactions coming about at the electrode/solution interface for vitamin E containing alcohol/water 1:1 (v/v) solutions. Moreover, it would be feasible to take into account a solvolysis reaction in competition with the hydrolysis one (C2), given that ethanol is also a potential nucleophile in this case, although we have no experimental evidences supporting it.

Due to the properties of the system studied in this work, compounds $\mathbf{C}, \mathbf{D}, \mathbf{E}, \mathbf{F}$ and $\mathbf{G}$ could not be characterized by conventional procedures. We believe that in situ surface based spectroscopic methods or addition of co-solvents or chemicals for enhancing solubility or trapping intermediates, respectively, would be promising strategies to get insight into the characteristics of still unknown compounds.

At the best of our knowledge, this was the first approach showing these electrochemical properties of vitamin $\mathrm{E}$ dissolved in alcohol-aqueous solutions.

\section{Acknowledgments}

This work was supported by Conselho Nacional de Desenvolvimento Científico e Tecnológico (CNPq, Brazil). C. Giacomelli is grateful to Coordenação de Aperfeiçoamento de Pessoal de Nível Superior (CAPES, Brazil).

\section{References}

1. Wolfa, R.; Wolfb, D.; Ruoccoc, V.; J. Eur. Acad. Dermatol. Venereol. 1998, 10, 103.

2. Webster, R. D.; Electrochem. Commun. 1999, 1, 581.

3. Mukai, K.; Okade, K.; Hosose, H.; J. Org. Chem. 1989, 54, 557.

4. Rosenau, T.; Habicher, W. D.; Tetrahedron 1995, 51, 7919.

5. Suarna, C.; Craig, D. C.; Cross, J.; Southwell-Keely, P.; J. Org. Chem. 1988, 53, 1281.

6. Witkowski, S.; Poplawski, J.; Pol. J. Chem. 1996, 70, 1448.

7. Rosenau, T.; Habicher, W. D.; Potthast, A.; Kosma, P.; Synlett 1999, 291.

8. Rosenau, T.; Habicher, W. D.; Chem. Pharm. Bull. 1997, 45, 1080.

9. Rosenau, T.; Habicher, W. D.; Tetrahedron Lett. 1997, 38, 5959.
10. Nagata, Y.; Miyamoto, C.; Matsushima, Y.; Matsumoto, S.; Chem. Pharm. Bull. 2000, 48, 71.

11. Nagata, Y.; Miyamoto, C.; Matsushima, Y.; Matsumoto, S.; Chem. Pharm. Bull. 1999, 47, 923.

12. Giacomelli, C.; Galato, D.; Ckless, K.; Spinelli, A.; J. Braz. Chem. Soc. 2002, 13, 332.

13. Lemanska, K.; Szymusiak, H.; Tyrakowska, B.; Zielinski, R.; Soffers, A. E. M. F.; Rietjens, M. C. M.; Free Radical Biol. Med. 2001, 31, 869.

14. Wain, A. J.; Wadhawan, J. D.; France, R. R.; Compton, R. G.; Phys. Chem. Chem. Phys. 2004, 6, 836.

15. Mukai, K.; Kageyama, Y.; Ishida, T.; Fukuda, K.; J. Am. Chem. Soc. 1989, 54, 557.

16. Parker, V. D.; J. Am. Chem. Soc. 1969, 91, 5380.

17. Svanholm, U.; Bechgaard, K.; Parker, V. D.; J. Am. Chem. Soc. 1974, 96, 2409.

18. Giacomelli, C.; Zaccaron, C. M.; Giacomelli, F. C.; Spinelli, A.; XIII Simpósio Brasileiro de Eletroquímica e Eletroanalítica, Araraquara/SP, 2002.

19. Zhang, T.-Y.; Zhu, S.-M.; Anal. Chim. Acta 1995, 309, 111.

20. Kim, O.-S.; Kusuda, K.; Bioelectrochem. Bioenerg. 1994, 33, 61.

21. Jaiswal, P. V.; Ijeri, V. S.; Srivastava, A. K.; Anal. Chim. Acta 2001, 441, 201.

22. Hart, J. P.; Trends Anal. Chem. 1986, 5, 20.

23. Sawyer, D. T.; Sobkowiak, A.; Roberts Jr., J. L.; Electrochemistry for Chemists, 2nd ed., John Wiley \& Sons Inc.: New York, 1995.

24. Kissinger, P. T.; Heineman, W. H.; Laboratory Techniques in Electroanalytical Chemistry, 2nd ed., Marcel Dekker Inc.: New York, 1996.

25. Marcus, M. F., Hawley, M. D.; J. Org. Chem. 1970, 35, 2185.

26. van Haaften, R. I. M.; Evelo, C. T. A.; Haenen, G. R. M. M.; Bast, A.; Biochem. Pharmacol. 2001, 61, 715.

27. Frampton, V. L.; Skinner, W. A.; Bailey, P. S.; J. Am. Chem. Soc. 1952, 76, 282.

28. Cheng, Z. Y.; Ren, J.; Li, Y. Z.; Chang, W. B.; Chen, Z. D.; Redox Report 2002, 7, 395.

29. Sierra, C.; Paster, M. C.; De Ramon, M.; Clin. Chim. Acta 1992, 15, 119.

Received: January 7, 2004 Published on the web: September 16, 2004 